This is an Accepted Manuscript of an article published by Taylor \& Francis in Building

Research and Information on 31/03/2016, available online:

http://www.tandfonline.com/doi/full/10.1080/09613218.2016.1153355

\title{
The impact of regulations on overheating risk in dwellings
}

\author{
Mark Mulville* \\ University of Greenwich \\ Department of Built Environment - King William Building \\ Old Royal Naval College \\ Park Row \\ Greenwich SE10 9LS \\ Phone: 02083319973 \\ E-mail: $\underline{\text { m.mulville@greenwich.ac.uk }}$ \\ Spyridon Stravoravdis \\ University of Greenwich \\ Department of Built Environment - King William Building \\ Old Royal Naval College \\ Park Row \\ Greenwich SE10 9LS \\ Phone: 02083319332 \\ E-mail: S.Stravoravdis@greenwich.ac.uk
}

*Author for correspondence 
The impact of regulations on overheating risk in dwellings

\begin{abstract}
Many new and emerging regulations and standards for buildings focus on climate change mitigation through energy and carbon reduction. In cool climates, such reductions are achieved by optimising the building for heat retention. It is increasingly recognised however that some degree of climate change is now inevitable and new and existing buildings need to consider this to ensure resilience and an ability to adapt over time. In this context the current approach to regulation which largely remains focused on the 'point of handover' may not be fit for purpose.

This paper focuses on a 'typical' dwelling designed to a range of standards, representing current or emerging approaches to minimising energy use, using a range of construction methods, where a number of adaptations are available to occupants. It considers, through the use of building performance simulation, how each configuration is likely to perform thermally over time given current climate change predictions.
\end{abstract}

The paper demonstrates that the current approach to assessing overheating risk in dwellings, coupled with the regulatory focus on reducing energy consumption, could result in significant levels of overheating. This overheating could, in the near future, present a risk to health and result in the need for significant interventions.

Keywords: Adaptation, Building Regulations, Building Simulation, Climate Change, Dwellings, Overheating 


\section{Introduction}

The Committee on Climate Change (2014) noted that one fifth of homes in England could already experience overheating (in a mild summer) and that this percentage is likely to increase in a warming climate and therefore called for new building standards to be developed to address the overheating risk in dwellings. Parry, Canziani, Palutikof, van der Linden and Hanson (2007) reported that the 2003 heat wave in Europe accounted for in the region of 35,000 excess deaths. This increased mortality was related to high internal temperatures over an extended time period (Wright, A., Young, A. \& Natarajan, S., 2005) and affected the most vulnerable in society, such as the elderly, infants and those with underlying health problems (Johnson et al., 2005). If such events are to become more common (which is predicted, with a similar event affecting southern Europe in 2007), this could have significant consequences for health, housing design (Wright, Young \& Natarajan 2005) and arguably the regulatory framework in the built environment.

The building regulations primary focus is one of health, safety and wellbeing. The growing realisation though, that $\mathrm{CO}_{2}$ emissions associated with the built environment can have a significant negative impact on the environment and contribute to climate change (in 2009 buildings were responsible for $43 \%$ of all $\mathrm{CO}_{2}$ emissions in the UK (Department for Communities and Local Government [DCLG], 2015)), has resulted in the requirements of national and regional legislation (such as the UK Climate Change Act and The European Energy Performance of Buildings Directive) being interpreted through building regulations. In recent years building regulations in the UK (UK Part L revisions 2010 and 2013) (see Figure 1), EU (European Energy Efficiency Directive) and indeed globally (Dubai Green Building Regulations and Specifications, Green Building Code of Peoples Republic of China) have increasingly sought to set more stringent energy performance targets. In cool or temperate climates such as mid-latitude and northern Europe, characterised by extended winter heating seasons, these regulations aim to mitigate the worst effects of climate change by reducing $\mathrm{CO}_{2}$ emissions and 
optimising buildings for heat retention. However, as noted by McLeod, Hopfe and Kwan (2013) it is being increasingly recognised that higher global emissions scenarios are becoming more likely, increasing the risk of greater levels of warming. As a result, it has been suggested that dwellings in cool climates may in the future suffer from overheating and indeed there is evidence that this may already be happening (Dengel \& Swainson, 2012). De Wilde and Coley, (2012) in a review of the implications of climate change for buildings, point out that the rationale and requirements of the building regulations in relation to overheating are largely based on historic data and may not therefore enable a realistic assessment of the potential future overheating risk.

Taking this into consideration this paper explores the idea that the current focus of increased levels of insulation and other heat loss reduction measures for new or recently constructed dwellings may, at least during warm periods, be counterproductive. As noted by Eames, Kershaw and Coley (2011) overheating could have severe health implications and as such could result in uninhabitable buildings that are technically obsolete due to the 'locked-in' (de Wilde \& Tian, 2011) impacts of climate change. The paper, supported by detailed probabilistic predictions, demonstrates the level of overheating that could be experienced depending on the standard or regulation the dwelling is constructed to and suggests how an alternative, more robust approach, to overheating risk assessment could be developed.

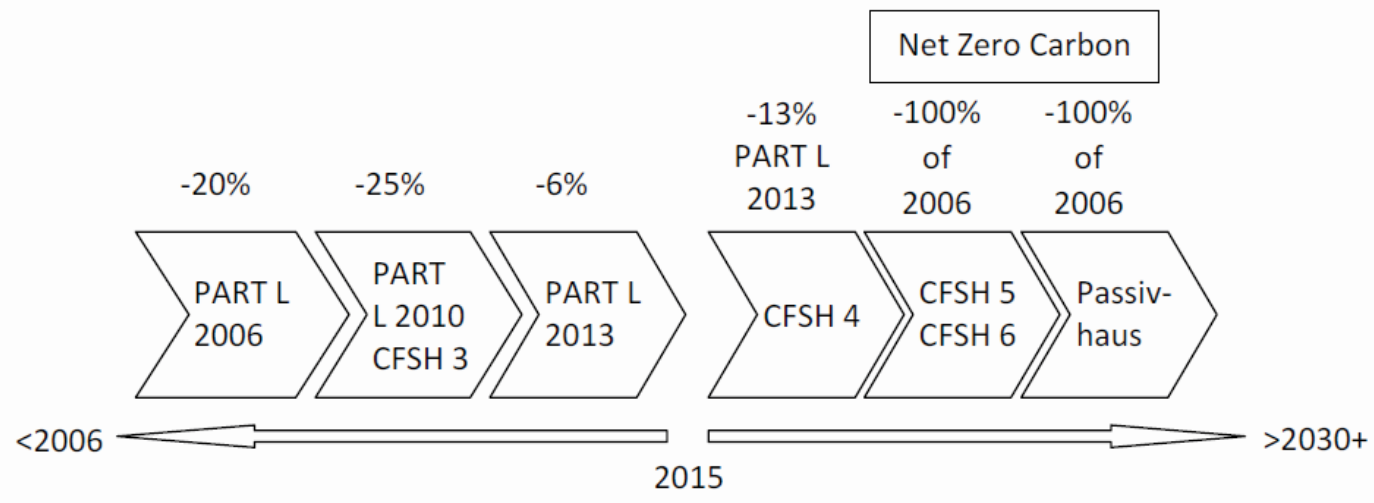

Figure 1 Timeline of energy related regulations and emerging standards (UK) including energy reduction targets 


\section{Background}

\section{Evidence of Overheating}

Until recently the general assumption in relation to domestic overheating has been that older dwellings were more vulnerable, with increased levels of insulation protecting new dwellings from such issues (Dengel \& Swainson 2012). However, there is now increasing evidence that new and low energy dwellings may suffer significant problems in the future and indeed that many such dwellings may already experience high levels of overheating (Dengel \& Swainson 2012, Mavrogianni, Taylor, Davies, Thoua \& Kolm-Murray 2015, Peacock, Jenkins \& Kane 2010, Rodrigues, Gillott \& Teltow, 2013). It has been suggested that light weight, air tight dwellings with little access to cross ventilation (such as single aspect flats) may be at a particularly high level of risk of overheating (Dengel \& Swainson 2012).

What is clear is that overheating presents a significant risk to dwellings and occupant health and that this could impact a wide range of buildings and building types. Using probabilistic assessment, Jenkins et al. (2014) found that by the 2030 s up to $76 \%$ of flats and $29 \%$ of detached dwellings could be at risk of overheating. Furthermore, Rodrigues et al. (2013) in a study considering the performance of a low-energy steel frame house design under current and future weather scenarios found that the building could be uncomfortably warm for $30 \%$ of the year.

As noted by de Wilde and Coley (2012), there appears to be at least some debate in relation to highly insulated buildings with Crawley (2008) noting greater resilience and Wang, Chen and Ren (2010) noting less resilience to the impacts of climate change. Gupta and Gregg (2012) cite the Passiv-on project which found that the high levels of insulation is Passive House buildings in southern Europe worked to keep the building cool during warm weather. However, McLeod et al. (2013) cites a number of studies (Larsen \& Jensen 2011, Mlecnik et al. 2012, Schnieders 2005) in relation to Passive House dwellings in several European locations where it is noted that there may 
be a risk of overheating in the current climate unless a number of alterations including active cooling were implemented. McLeod et al. (2013) does however point out that Passive House dwellings may offer marginally more protection from overheating than other highly insulated options (Findings for the 2050 s heavy weight passive house greater than $25^{\circ} \mathrm{C}$ for $6.6 \%$ of the year whereas a heavy weight 'well insulated' building greater than $25^{\circ} \mathrm{C}$ for $8.2 \%$ of the year). The core reasons for these differences are unclear, although Gupta and Gregg (2012) when considering a range of 'typical' dwelling types in Oxford found insulation position to be of importance. As such insulation may be a 'double edged sword' (Hacker, Holmes, Belcher \& Davies 2005) with increased insulation reducing winter heat loss but increasing overheating risk especially in air tight buildings where it is difficult to dissipate internally generated gains. This is further supported by Orme and Palmer (as cited in Dengel \& Swainson, 2012) who noted that increasing the level of insulation in dwellings resulted in higher levels of overheating.

Peacock et al. (2010) note the potential for increased internal gains through the proliferation of electronic devices in the home which could lead to higher internal temperatures. They go on to note that despite this climatic effects are still likely to be more influential than internal gains and for the UK such internal gains are likely to remain useful throughout the heating season. Building on this, it can be argued that measures designed to mitigate future climate change must also take account of the impact these measures may have on overheating risk, the research presented in this paper attempts to take this into consideration. There is evidence that behavioural and technical adaptations may at least in some part be able to address overheating risk (Coley, Kershaw \& Eames, 2012) however, as noted by Hills (2012) for low-income households any requirement for technical intervention through artificial cooling may result in summer fuel poverty. This is particularly important for countries like the UK as installed cooling capacity remains low (Hulme, Beaumont \& Summers, 2011). 


\section{Overheating Adaptation}

A number of authors have explored potential solutions to overheating in domestic buildings (for example see Gupta \& Gregg, 2012, Porritt, Cropper, Shao \& Goodier, 2012, van Hoff, Blocken, Henson \& Timmermans, 2015). These studies found that adaptation measures such as shutters and fixed shading, reductions in solar/fabric gains, increased surface albedo and the use of thermal mass may help reduce future overheating, although the magnitude of the influence of thermal mass has been questioned (Kendrick, Odgen, Wang \& Baiche 2012). Gupta and Gregg (2012) found that user controlled shading, surface albedo and thermal mass, could help reduce overheating risk although it was also found that no 'passive' measures alone could completely remove the risk and that behavioural and active measures may also be needed. Jones, Mulville and Brooks (2013) set out an approach to adaptation planning related to the potential impact of climate change where the lifecycle of the building is taken into consideration. It suggests that where risks are identified at the design stage an adaptation plan can be developed and where such adaptations in the future may otherwise prove prohibitively expensive, preparatory or enabling works can be carried out during the construction phase to enable the future adaptation. As noted by Gupta and Gregg (2012) mitigation measures to reduce the contribution of the built environment to climate change, and adaptation measures, to allow the building to adapt to climate change that does occur, should not negatively impact on the performance of the building. Combining the adaptation planning approach suggested by Jones et al. (2013) with the measures that have been shown to reduce overheating risk may have the potential to ensure the buildings can perform over time. In such a scenario adaptation measures are enabled at the design stage but only implemented when needed, therefore not having a negative impact on current performance (such as increasing winter heat load due to increased solar shading). 


\section{Literature Review}

\section{The Regulatory Framework}

In the UK, building regulations do not stipulate a single maximum temperature in the workplace or in the home. For domestic buildings, checks are required at the design stage, comparing mean summer internal temperature to a threshold temperature (using the Standard Assessment Procedure (SAP)) to assess the risk of overheating (Zero Carbon Hub, 2015). Further guidance, which does refer to specific temperature is provided by the Chartered Institution of Building Services Engineers (CIBSE, 2015), but this is beyond the requirements of the regulations. The UK Workplace (Health, Safety and Welfare) regulations (Health and Safety Executive, 2013) specify minimum but not maximum temperatures in the workplace, the same standards do not exist for private residential buildings but minimum and maximum temperatures may apply to other residential type buildings (see for example Northern Irelands Residential Care Homes, minimum standards (Department of Health, Social Services and Public Safety, 2011)).

By way of comparison, for new dwellings, the Danish Code for Indoor Thermal Climate (DS 474), sets a maximum of 100 hours not in excess of $26^{\circ} \mathrm{C}$ and not more than 25 hours above $27^{\circ} \mathrm{C}$ calculated using a simple software tool (BE10) (Kunkel, Kontonasiou, Arcipowska, Mariottini \& Atanasiu, 2015) similar to the UK SAP. The Swedish Building Code sets minimum room temperatures and maximum surface temperatures, but not maximum room air temperatures (Krunkel et al., 2015). The Republic of Ireland follows a similar approach to that of the UK with the Dwelling Energy Assessment Procedure (DEAP) used to carry out an overheating risk assessment (Sustainable Energy Authority of Ireland, 2013), although this assessment is optional and not mandated by regulation. The Norwegian building regulations have implemented requirements for the consideration of solar gains in nondomestic buildings, but not domestic buildings (Schild, 2009). As can be seen from the above comparisons, set maximum summer temperatures for dwellings in cool climates are still uncommon. 
Where such standards do exist the assessment method used tends to be simplistic in nature and as will be discussed below, may not be fit for purpose.

\section{Metrics}

There remains considerable discussion in regard to the most appropriate metrics for defining overheating (de Dear, Kim, Candido \& Deuble 2015, de Wilde \& Tian 2011, Hacker et al., 2005, Nicol \& Spires, 2013) with the merits of single temperature exceedance or traditional approach versus adaptive comfort standards (Nicol \& Spires, 2013), considerations of potential health and mortality impacts (Dengel \& Swainson 2012, Jenkins et al. 2014) along with considerations of the relevant importance of night time temperatures (Dengel \& Swainson 2010, Peacock et al., 2010), forming the main points of discussion.

The main criticism of the single temperature exceedance method (which set an allowable exceedance of $1 \%$ of occupied hours above a given temperature) is that there is evidence of a correlation between acceptable internal temperatures and the external temperature (Nicol \& Humphreys, 2010) and as such the comfort range is in reality a moving target that a single temperature criterion cannot take account of. Furthermore, a single temperature criterion does not give an indication of the severity of overheating experienced while the adaptive comfort approach considers both severity and length of exposure (Nicol \& Spires, 2013). Length of exposure is of particular importance in relation to potential health impacts with, as previously noted, many of the premature deaths associated with the 2003 European heat wave being related to the extended period of high temperatures (Wright et al., 2005). The adaptive thermal comfort approach as detailed by Nicol and Humphreys (2010) is built on field studies that note the ability of occupants to adapt to climatic changes, whereas the temperature exceedance approach, it could be argued assumes a more passive approach taken by occupants. However, as noted by Beizaee, Lomas and Firth (2013), EN15251 which forms the basis of the adaptive comfort approach for 'free running' buildings was developed primarily for commercial buildings and the adaptations available for 
occupants of dwellings are significantly different to those of an office. Furthermore, Mavrogianni et al. (2015) question how under such conditions vulnerable and potentially immobile people may be able to adapt. It has been noted (Roaf, Brotas \& Nicol, 2015) that the single temperature exceedance method (in comparisons to the adaptive comfort method) would appear to overestimate the overheating risk and that in reality the risk may be lower than many studies in this field have predicted. With the potential health risks associated with overheating such assertions need to be approached with caution and as suggested by Mavrogianni et al. (2015) it may be wise to combine the adaptive comfort approach with a static overheating criterion.

What is clear from the literature is that high temperatures in bedrooms overnight are a significant risk (Naughton et al. 2002 as cited in Peacock et al., 2010) and that temperatures above $24^{\circ} \mathrm{C}$ may begin to impair sleep and have other associated health impacts (Dengel \& Swainson 2012). With the lack of a clear definition of overheating in dwellings, studies in this area are as a result subject to a degree of uncertainty (Dengel \& Swainson 2012).

\section{Overheating Assessment Methods}

In addition to a lack of clarity regarding the appropriate metrics used to define overheating there is evidence that the current methods of assessing overheating risk in dwellings may not be reliable (Jenkins, Ingram, Simpson \& Patidar, 2013). It has been noted that much of the data used to analyse current overheating risk comes from the past (de Wilde \& Coley, 2012) and therefore does not make allowance for the potential impacts of a changing climate. The overheating prediction method currently used in the Standard Assessment Procedure (SAP) (Department of Energy and Climate Change [DECC], 2014) assigns a level of risk to potential overheating, where higher levels of overheating are detected the assessor has the option to use window opening to alleviate these problems (window opening may help to reduce overheating by increasing the ventilation rate, which will reduce the ambient room temperature where outside air is cooler and can also help aid personal 
cooling through the evaporation of moisture form the skin). Although this may be suitable in rural areas, in areas subject to high levels of pollution and noise (Mavrogianni et al. 2015) this may be unrealistic and in both cases (urban and rural) such an approach may present a security risk (Mavrogianni, Wilkinson, Davies, Biddulph \& Oikonomou 2012). This is supported by the findings of Skinner and Grimwood (2005) who note that $54 \%$ of dwellings in the UK during the day-time and 67\% during night-time are exposed to noise levels in excess of World Health Organisation (WHO) guidelines. In addition there are strong safety related arguments for the inclusion of restrictors on upper floor windows (McLeod et al. 2013) which reduce the potential for increased ventilation. As such, the reliance on window opening may be over optimistic and furthermore as suggested by several authors (for example see Peacock et al. 2010 and Roaf et al. 2015) there may, in the future, be an upper limit to the effectiveness of window opening in reducing overheating.

The Passive House Standard, as developed by the 'Passivhaus Institut' (Cotterell \& Dabeby, 2012) (http://www.passiv.de), uses a separate method of overheating risk assessment administered through the Passive House Planning Pack (PHPP). Although, like the other standards discussed here, the data contained in PHPP is from the past, the exceedance limitation of $25^{\circ} \mathrm{C}$ for a maximum of $10 \%$ of the year (Feist, W. 2013) assessed through PHPP, would appear to be more robust than the SAP assessment method (below $23.5^{\circ} \mathrm{C}$ ) as it is not based on a reliance on window opening.

\section{Building Performance Simulation}

In most cases of overheating risk assessment at the design stage, there is some form of building performance prediction, usually through building performance simulation (such as the compliance assessments used in SAP and PHPP or dynamic simulation more commonly used in research such as that of Coley at al. (2012)). Although widely used, there are some significant uncertainties that must be taken into account when considering building simulation based performance assessments. As noted by de Wilde and Tian (2011) this includes modelling, numerical and specification uncertainty 
along with scenario uncertainties related to occupant behaviour and, when considering performance over time, predicted climatic conditions and likely renovation scenarios. Future weather files are a key component of any climate change impact study using building simulation. In the UK, the data used to generate such weather files (as used in building simulation studies) originates from the UK Climate Change Projections (UKCP) (Jenkins et al. 2009). It has been argued that due to the inherent difficulty in predicting future weather scenarios a probabilistic approach should be taken (de Wilde \& Tian, 2011) and in that sense the UKCP09 offers a significant advantage over the previous UKCP02 as it offers a wide range of probabilistic scenarios. This has the knock on impact of introducing additional complication to such prediction due to the required processing. With the goal of addressing this, the PROMETHEUS project at the University of Exeter developed a range of weather data files based on the UKCP09 predictions which represent a range of probabilities $\left(10^{\text {th }}, 50^{\text {th }}\right.$ and $90^{\text {th }}$ percentile for low, medium and high scenarios) for three timescale (2030s, 2050s and 2080s) producing both Test Reference Years (TRYs) to represent a 'normal' year and Design Summer Years (DSYs) to represent a 'near extreme' year. The methods used to develop the files are detailed by Eames et al. (2011). Several studies considering domestic overheating have used these weather data files (for example see Coley et al., 2012, Gupta \& Gregg, 2012, Mavrogianni et al., 2012) and although the methods used to develop the files reduces the computing needed some considerations remain in relation to how the files are implemented in climate change impact studies. Gupta and Gregg (2012) suggest that climate impact studies carried out using worst case scenarios $\left(90^{\text {th }}\right.$ percentile) would ensure resilient designs. Coley et al. (2012) however, suggest that a more median approach ( $50^{\text {th }}$ percentile) with allowance only for 'hard' adaptations to resolve any overheating, as this would allow designers to avoid potentially unnecessary and costly adaptations. Jenkins et al. (2013) suggest that both the DSYs, which is intended to test the building for overheating and TRYs, used to represent more normal conditions for energy estimates, be used so that both 'near extreme' and higher probability scenarios can be represented. This in turn allows for at least some of the 
probabilistic capabilities of UKCP09 to be realised, although as noted by Coley et al. (2012) for some UK cities DSYs may show a cooler climate than TRYs and use of DSYs therefore should be approached with caution.

\section{Methodology}

For this research, five building standards were chosen to represent a range of construction specifications, requiring increasing levels of energy savings. This included the regulatory minimums of Part L 2006 and 2010, the voluntary standards of the Code for Sustainable Homes (CfSH) levels four and five and the Passive House Standard. Figure 1 depicts how the energy consumption predictions for each standard noted relate to each other. As can be seen they follow the push towards 'net zero carbon' dwellings in the UK (National House Building Council Foundation, 2009) and although this has recently been put on hold (Her Majesty's [HM] Treasury, 2015) it is likely to remain a long term goal.

Once the relevant standards were established a 'typical' UK dwelling was developed based on a dwelling stock analysis of England and the wider UK. This indicated that since $2001,66 \%$ of dwellings constructed were houses (DCLG, 2014a and National House Building Council 2014), approximately one third of these were semi-detached, with an average of three bedrooms and an average floor area of 91.7sqm (DCLG, 2014b). Of the total dwelling stock in England and Wales (24.6 million, DCLG, 2014c and Statistics for Wales, 2015) 30\% or 7.38 million are semi-detached houses (Office of National Statistics, 2011). Although flats/apartments and particularly single aspect flats have been shown to be at high risk of overheating (Mavrogianni et al. 2015) and several studies have explored these issues (Dengel \& Swainson 2012), detailed exploration of the impact on houses are less prevalent and given the volume of dwellings involved $(7.38 \mathrm{~m})$ consideration of the potential impacts on these units is merited. Following this, a three bedroom semi-detached property aligning with 
these criteria, with a glazing ratio of $22.5 \%$ and layout based on Roberts-Hughes's (2011) 'case for space' guidelines was chosen to represent the 'typical' dwelling.

The dwellings did not include solar shading, other than in places where the regulation or standard in question required it. It is accepted that details of design will have a significant impact on overheating risk and it is a limitation of this work that the 'typical' case presented here cannot be fully representative of the stock of semi-detached dwellings. The criteria used aim to ensure that the 'typical' case reflects the likely approach to delivering such dwellings built to the standards and regulations under consideration in this paper.

The fabric specifications of the dwellings were developed in accordance with the relevant compliance assessment for the given standard (SAP (DECC, 2014) for Part L, Passive House Planning Pack (Feist, 2013) for Passive House and the DCLG (2011) recommendations for the Code for Sustainable Homes for CfSH level four and CfSH level five). For each specification three variants were established, representing three levels of thermal mass, and three different construction methods: low mass $\sim 100 \mathrm{~kJ} / \mathrm{m}^{2} \mathrm{~K}$, medium mass $\sim 250 \mathrm{~kJ} / \mathrm{m}^{2} \mathrm{~K}$ and high mass $\sim 450 \mathrm{~kJ} / \mathrm{m}^{2} \mathrm{~K}$, based on SAP 2012 (DECC, 2014). Predicted internal loads were then established in accordance with CIBSE Guide A (CIBSE, 2015). Details of the specifications used can be found in Table 1. 
Table 1 Model Input Parameters

\begin{tabular}{|c|c|c|c|c|c|c|}
\hline Element & Units & Part L 2006 & Part L 2010 & CFSH 4 & CFSH 5/6 & $\begin{array}{l}\text { Passive } \\
\text { House }\end{array}$ \\
\hline $\begin{array}{l}\text { Roof } \\
\text { U-Value }\end{array}$ & $\mathrm{W} / \mathrm{m}^{2} \mathrm{~K}$ & 0.18 & 0.15 & 0.13 & 0.1 & 0.1 \\
\hline $\begin{array}{l}\text { Wall } \\
\text { U-Value }\end{array}$ & $\mathrm{W} / \mathrm{m}^{2} \mathrm{~K}$ & 0.28 & 0.23 & 0.18 & 0.15 & 0.15 \\
\hline $\begin{array}{l}\text { Floor } \\
\text { U-Value }\end{array}$ & $\mathrm{W} / \mathrm{m}^{2} \mathrm{~K}$ & 0.2 & 0.18 & 0.15 & 0.1 & 0.1 \\
\hline $\begin{array}{l}\text { Window } \\
\text { U-Value }\end{array}$ & $\mathrm{W} / \mathrm{m}^{2} \mathrm{~K}$ & 1.8 & 1.4 & 1.4 & 1.1 & 0.8 \\
\hline $\begin{array}{l}\text { Window G- } \\
\text { Value }\end{array}$ & $0-1$ & 0.72 & 0.64 & 0.64 & 0.60 & 0.54 \\
\hline $\begin{array}{l}\text { Air } \\
\text { Permeability }\end{array}$ & $\begin{array}{l}\mathrm{m}^{3} / \mathrm{hr} / \mathrm{m}^{2} \\
\text { @50pa }\end{array}$ & 10 & 5 & 3 & 1 & 0.7 \\
\hline $\begin{array}{l}\text { Ventilation } \\
\text { Rate }\end{array}$ & As noted & $271 / s$ & $271 / s$ & $271 / s$ & $271 / s$ & $30 \mathrm{~m}^{3} / \mathrm{hr} / \mathrm{p}$ \\
\hline $\begin{array}{l}\text { Thermal } \\
\text { Bridging }\end{array}$ & $\mathrm{W} / \mathrm{m}^{2} \mathrm{~K}$ & 0.15 & 0.08 & 0.06 & 0.04 & 0.04 \\
\hline \multicolumn{7}{|c|}{ Window Position Ventilation Rate* } \\
\hline Notes: & $\begin{array}{l}\text { For the 'typi } \\
\text { shading devi } \\
\text { Passive Hou } \\
\text { building witl } \\
\text { Mass was va } \\
\text { frame const } \\
\text { between lov }\end{array}$ & $\begin{array}{l}\text { ' building to } \\
\text { was includec } \\
\text { Air Permeabi } \\
\text { volume of } 21 \\
\text { d by choosin } \\
\text { ind high mass }\end{array}$ & $\begin{array}{l}\text { mply with Pas } \\
\text { n the South } \\
\text { y of } 0.7 \text { relate } \\
65 \mathrm{~m}^{3} \\
\text { between raise } \\
\text { Il constructio } \\
\text { arty walls ano }\end{array}$ & $\begin{array}{l}\text { ive Hous } \\
\text { çade (or } \\
\text { to } 0.6 \text { ai } \\
\text { timber } \\
\text { and bloc } \\
\text { nternal }\end{array}$ & $\begin{array}{l}\text { heating crit } \\
\text { for alternati } \\
\text { ges per hou } \\
\text { and slab on } \\
\text { with extern } \\
\text { ns. }\end{array}$ & $\begin{array}{l}\text { a } 600 \mathrm{~mm} \\
\text { rientation) } \\
\text { 50pa for a } \\
\text { de, timber } \\
\text { isulation and }\end{array}$ \\
\hline
\end{tabular}

This 'typical' building was then modelled in 3D using the Ecotect ${ }^{\circledR}$ software (Marsh, 1996), before being exported to the Heat Transfer in Buildings 2 (HTB2) software (Lewis \& Alexander, 1990) for thermal performance simulation and analysis. Exporting to HTB2 was necessary as this software allows for more in depth analysis and also simulates the building dynamically as opposed to the admittance or steady state method used in Ecotect ${ }^{\circledR}$.

Once the various versions of the buildings had been developed, models were run using current and future probabilistic reference years based around the UKCP09 weather generator as developed by 
the PROMETHEUS project at the University of Exeter and detailed by Eames et al. (2011). For the purposes of this study the $50^{\text {th }}$ percentile predictions of the median scenario where used for both TRYs (representing the more likely prediction) and DSYs (representing near extreme predictions). It is accepted that using a range of predictions $\left(10^{\text {th }}, 50^{\text {th }}\right.$ and $90^{\text {th }}$ percentiles for low, medium and high scenarios) would give a wider indication of probability, however as Coley et al. (2012) note using the $50^{\text {th }}$ percentile provides a more median result, allowing for consideration of overheating risk while avoiding designing to the worst case scenario. Such an approach also reduces the risk of interventions made now, to avoid future overheating risk, increasing current energy use.

As building occupants are likely to adapt to warmer climates, four 'anytime' window opening scenarios (closed, slightly open, half open, fully open) and two night-time purge ventilation scenarios (half or fully open) were included in the simulations, with associated ventilation rates for each (see Table 1). The findings of the 'night purge' window positions are only included for the high thermal mass scenarios where they had the greatest impact. In each case the software used enabled the window opening position to be triggered by internal temperatures of $23.9^{\circ} \mathrm{C}$. This aligned to the work of Jenkins, Patidar, Banfill and Gibson (2011) who suggested that $23.9^{\circ} \mathrm{C}$ was the temperature at which occupants are likely to begin to adapt.

Along with building standard, thermal mass and ventilation rate (window position), orientation can be expected to have an impact on overheating risk. For this study two possible orientations were considered (North-South and East-West). These were chosen to reflect potential extremes of solar gain (high gains for South facing, but easier to control versus the East-West scenario). It is a limitation of the study that a wider range of orientations could not be considered, which arguably would be more representative of the as built stock.

Overall five building standards, built using three thermal mass variations, in two orientations with up to six possible window positions were simulated (see Table 2), along with some additional 
simulations for comparison between London and Edinburgh (a full set of scenarios/models were run for London with a selection for Edinburgh for comparative purposes) which resulted in 1788 individual model runs.

Table 2 Sample Modelling Plan (Part L 2010 - model images included for Illustration)
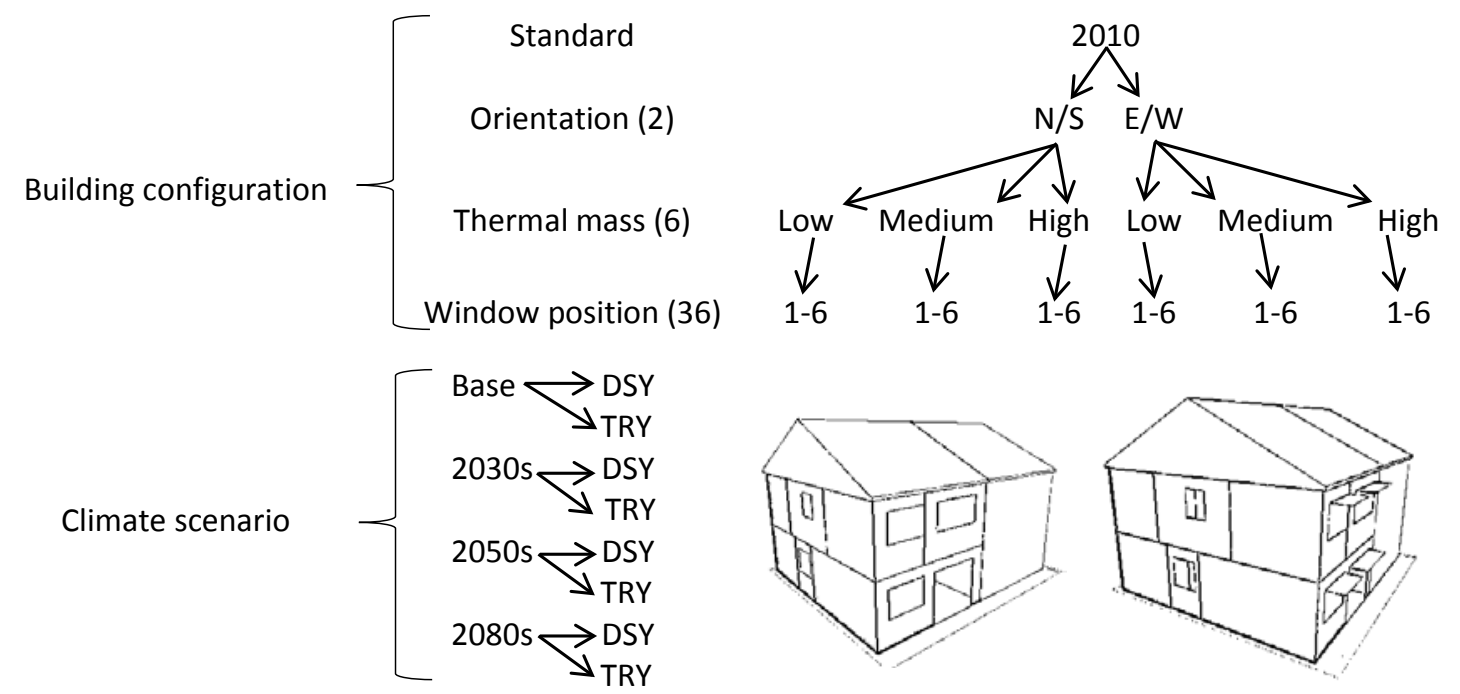

As discussed previously, there is some debate regarding the most appropriate metrics to be used for predicting overheating in free running dwellings. To allow for further comparison between the two most common approaches (single temperature exceedance and the adaptive comfort method) both were included in this study. Overheating criteria one, two and three are based on adaptive comfort standards as detailed by Nicol and Spires (2013) while criteria four and five are based on the more traditional single temperature exceedance criteria, the specifics of each of the criteria can be found in Table 3 . For each of the adaptive comfort criteria the threshold used is a function of the relationship between the running mean outdoor temperature and the indoor temperature. As the software used was not capable of calculating a running mean of temperature (directly at least) the data generated was exported and manually analysed to create a running mean thus allowing for consideration of the adaptive comfort measures. As noted by Nicol and Spires (2013), exceedance of any two of these criteria is considered to represent overheating. 
Table 3 Traditional and Adaptive Comfort Overheating Criteria

\section{Adaptive Comfort Method}

\begin{tabular}{|l|l|}
\hline Criteria 1* & $\begin{array}{l}\text { Limits the how often the internal temperature exceeds the comfort range (by 1K } \\
\text { for } 3 \% \text { of occupied hours) during the summer months (May to September } \\
\text { inclusive) }\end{array}$ \\
\hline Criteria 2* & $\begin{array}{l}\text { Considers the severity of overheating in any one day, based on how much the } \\
\text { space overheats (by how many degrees the space exceeds the prescribed } \\
\text { temperature) and for how long, again during the summer months }\end{array}$ \\
\hline Criteria 3* & $\begin{array}{l}\text { Sets an absolute maximum temperature which reflects the point at which normal } \\
\text { adaptations may be insufficient to ensure comfort }\end{array}$ \\
\hline
\end{tabular}

Traditional Method

\begin{tabular}{|l|l|}
\hline Criteria $4^{* *}$ & $\begin{array}{l}\text { Sets a limit of one percent of occupied hours above } 25^{\circ} \mathrm{C} \text {, which relates to the } \\
\text { temperature at which discomfort may begin }\end{array}$ \\
\hline Criteria $5^{* *}$ & $\begin{array}{l}\text { Sets a limit of one percent of occupied hours above } 28^{\circ} \mathrm{C} \text {, which relates to an } \\
\text { unacceptably high temperature }\end{array}$ \\
\hline
\end{tabular}

*Source: Nicol and Spires, 2013

**Source: Hacker et al., 2005

\section{Results}

Figure 2 displays the findings of the building simulations carried out for London (with a comparative for Edinburgh included in the 2080s) combining the building standard, thermal mass, window position and climatic scenario for a dwelling with either a North-South or East-West aspect. Although as noted by Coley et al. (2012) for some UK cities DSY (for testing near extreme) may show a cooler climate than TRY (for a more normal climate) this was not found to be an issue in this scenario as TRY was consistently cooler than DSY. As a result of this the findings presented in this section are based on DSYs only. 

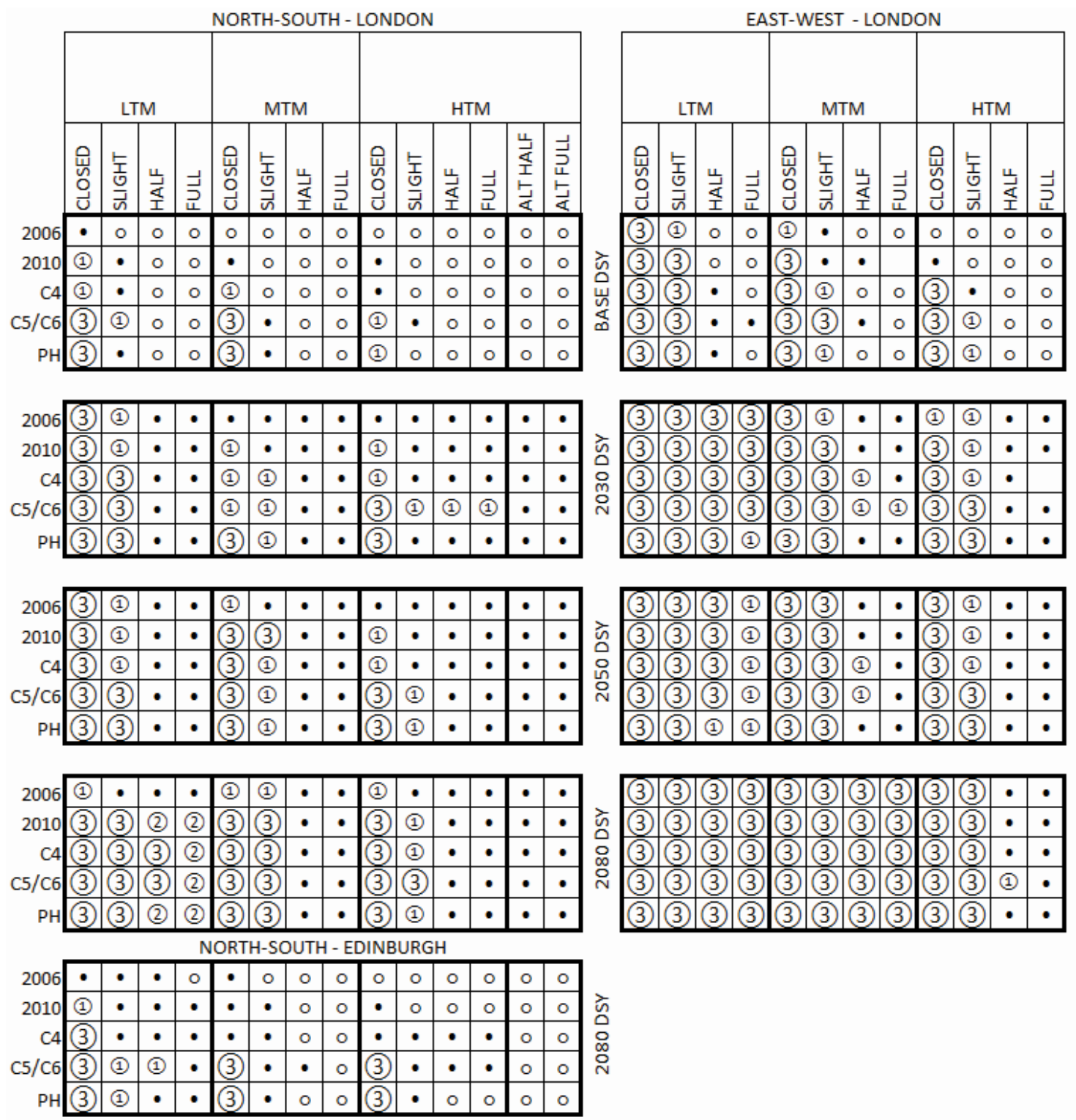

\begin{tabular}{|l|l}
\hline$(1)$ & $=$ Criteria 1 and 2 (Adaptive Comfort) exceeded in addition to criteria 4 and 5 (Traditional) \\
(2) & $=$ Criteria 2 and 3 (Adaptive Comfort) exceeded in addition to criteria 4 and 5 (Traditional) \\
(3) $=$ Criteria 1,2 and 3 (Adaptive Comfort) exceeded in addition to criteria 4 and 5 (Traditional)
\end{tabular}

Any of the above combinations is considered to represent an overheating issue under the adaptive comfort criteria (1-3)

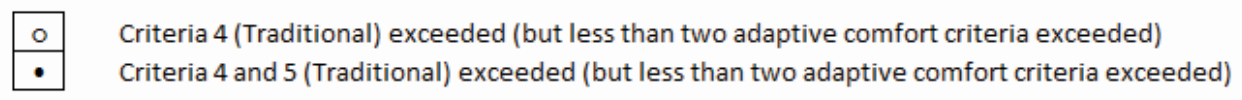

Details in relation to how criteria (1-5) are assessed can be found in Table $\mathbf{4}$ (and are discussed in the methodology)

Figure 2 Overheating Risk Assessment (semi-detached house, cross ventilation possible)

A number of initial observations can be drawn from the analysis, such as an increase in overheating over time, as can be seen in Table 4. Taking the CfSH level four, medium thermal mass, North-South 
orientation with slightly open windows possible and measured against exceedance of two of the three adaptive comfort criteria (criteria 1-3) no overheating occurs in the base case, however, for the 2030 s exceedance occurs $7.8 \%$ of the time, $11.1 \%$ for the 2050 s and $27.4 \%$ for the 2080 s. Interestingly, when measured against the more traditional steady state criteria (criteria 4), predicted overheating increases significantly (Base 25.2\%, 2030s 54.8\%, 2050s 64.8\% and 2080s 75\%) highlighting as noted by Roaf et. al. (2015) that the traditional criteria predict higher levels of overheating than adaptive comfort standards. This research did not explore the merits of the adaptive comfort versus traditional steady state overheating criteria in detail, for clarity the remainder of this study focuses on the adaptive comfort standards.

Table 4 CfSH 4 Overheating Risk as a percentage, during summer months (May-Sept)

\begin{tabular}{|c|c|c|c|c|c|c|c|c|c|c|c|c|}
\hline \multirow{3}{*}{$\begin{array}{l}\text { Overheating } \\
\text { Criteria } \\
\text { Window } \\
\text { Position }\end{array}$} & \multicolumn{4}{|c|}{ Low Thermal Mass } & \multicolumn{4}{|c|}{ Medium Thermal Mass } & \multicolumn{4}{|c|}{ High Thermal Mass } \\
\hline & \multicolumn{2}{|c|}{ Adaptive } & \multicolumn{2}{|c|}{ Traditional* } & \multicolumn{2}{|c|}{ Adaptive } & \multicolumn{2}{|c|}{ Traditional* } & \multicolumn{2}{|c|}{ Adaptive } & \multicolumn{2}{|c|}{ Traditional* } \\
\hline & 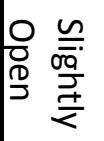 & $\begin{array}{ll}\frac{1}{0} \\
\frac{D}{D} \\
\frac{D}{J}\end{array}$ & 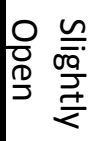 & 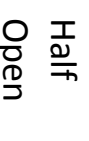 & 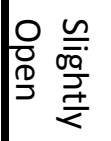 & $\begin{array}{ll}\frac{1}{2} \\
\frac{D}{D} \\
\frac{D}{2}\end{array}$ & 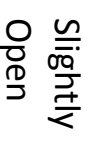 & $\begin{array}{l}\text { 옹 } \\
\text { 焉 }\end{array}$ & 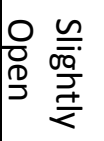 & $\begin{array}{l}\text { 웡 } \\
\frac{\mathrm{D}}{\mathrm{D}} \\
\frac{\mathrm{D}}{\mathrm{N}}\end{array}$ & 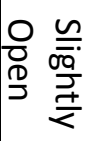 & $\begin{array}{l}\text { OO } \\
\end{array}$ \\
\hline Base & 1.3 & 0 & 31.1 & 14.8 & $\mathbf{0}$ & 0 & 25.2 & 12.2 & 0 & 0 & 24.5 & 11 \\
\hline 2030s & 18.3 & 5.8 & 55.8 & 34.4 & 7.8 & 1.9 & 54.8 & 32.8 & 2.6 & 0 & 53.8 & 32.7 \\
\hline 2050s & 20.2 & 9.1 & 66.6 & 41.7 & 11.1 & 2.6 & 64.8 & 39.6 & 4.5 & 0 & 63.8 & 40.5 \\
\hline 2080s & 42.4 & 11.7 & 77.5 & 55.1 & 27.4 & 3.2 & 75 & 52.8 & 19.6 & 0 & 74.7 & 53.3 \\
\hline
\end{tabular}

Notes: Traditional overheating criteria relates to criteria four only

Secondly, buildings with higher thermal mass are at less risk of overheating than more light weight buildings when construction standard built to is kept constant (for instance built to CfSH level four, but thermal mass varied) (see Table 5). Taking Part L 2010 as an example, in the 2030s higher thermal mass can help to reduce incidents of overheating by up to $15 \%, 15.6 \%$ in the 2050 s and $19.6 \%$ in the 2080s (all based on slightly open windows when temperatures are appropriate to take advantage of thermal mass). Furthermore, thermal mass becomes more important as insulation levels increase, while at higher levels of insulation (CfSH level five and Passive House) the benefit of 
thermal mass reduces between the 2050s and 2080s as the climate warms. This is based on the difference in percentage of overheating observed between the low and high thermal mass versions across the building standards as noted in Table 5.

Table 5 Overheating Risk as a percentage of occupied hours during summer months (Slightly open wins $-\mathrm{N} / \mathrm{S}$ )

\begin{tabular}{|c|c|c|c|c|c|c|c|c|c|c|c|c|c|c|c|}
\hline & \multicolumn{3}{|c|}{ Part L 2006} & \multicolumn{3}{|c|}{ Part L 2010} & \multicolumn{3}{|c|}{ CfSH 4} & \multicolumn{3}{|c|}{ CfSH 5} & \multicolumn{3}{|c|}{ Passive House } \\
\hline $\begin{array}{l}\text { Thermal } \\
\text { Mass }\end{array}$ & § & 王 & 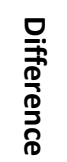 & ڤ̊ & $\stackrel{I}{\underline{\underline{D}}}$ & 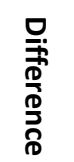 & §̊ & $\frac{I}{\underline{\underline{\sigma g}}}$ & 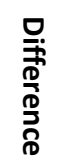 & §̊ & 吾焉 & 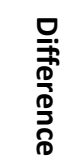 & §̊ & $\frac{I}{\underline{\underline{\sigma g}}}$ & 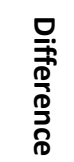 \\
\hline Base & 0 & 0 & 0 & 0 & 0 & 0 & 1.3 & 0 & 1.3 & 11.7 & 0 & 11.7 & 7.8 & 0 & 7.8 \\
\hline $2030 s$ & 5.9 & 0 & 5.9 & 15 & 0 & 15 & 18.2 & 2.6 & 15.6 & 35.9 & 15 & 20.9 & 31.3 & 11.7 & 19.6 \\
\hline $2050 \mathrm{~s}$ & 11.1 & 2.6 & 8.5 & 15.6 & 0 & 15.6 & 20.2 & 4.5 & 15.7 & 41.8 & 21.5 & 20.3 & 36 & 15 & 21 \\
\hline $2080 \mathrm{~s}$ & 13 & 5.2 & 7.5 & 32 & 12.4 & 19.6 & 42.4 & 19.6 & 22.8 & 61.4 & 45 & 16.4 & 58.1 & 41 & 17.1 \\
\hline
\end{tabular}

This reduction in the benefit of thermal mass is likely a result of the decrease in diurnal temperature ranges over time and, as can be seen in Figure 3, the general reduction in the difference between internal and external temperatures. This has the impact of reducing the ability of ventilation and thermal mass to store or transfer energy to the cooler outside air. Figure $\mathbf{3}$ also demonstrates that along with the potential for increased overheating over time, temperatures in excess of $24^{\circ} \mathrm{C}$ in bedrooms at night time may be regularly experienced from the 2030 s onwards, which presents a particular cause for concern. 


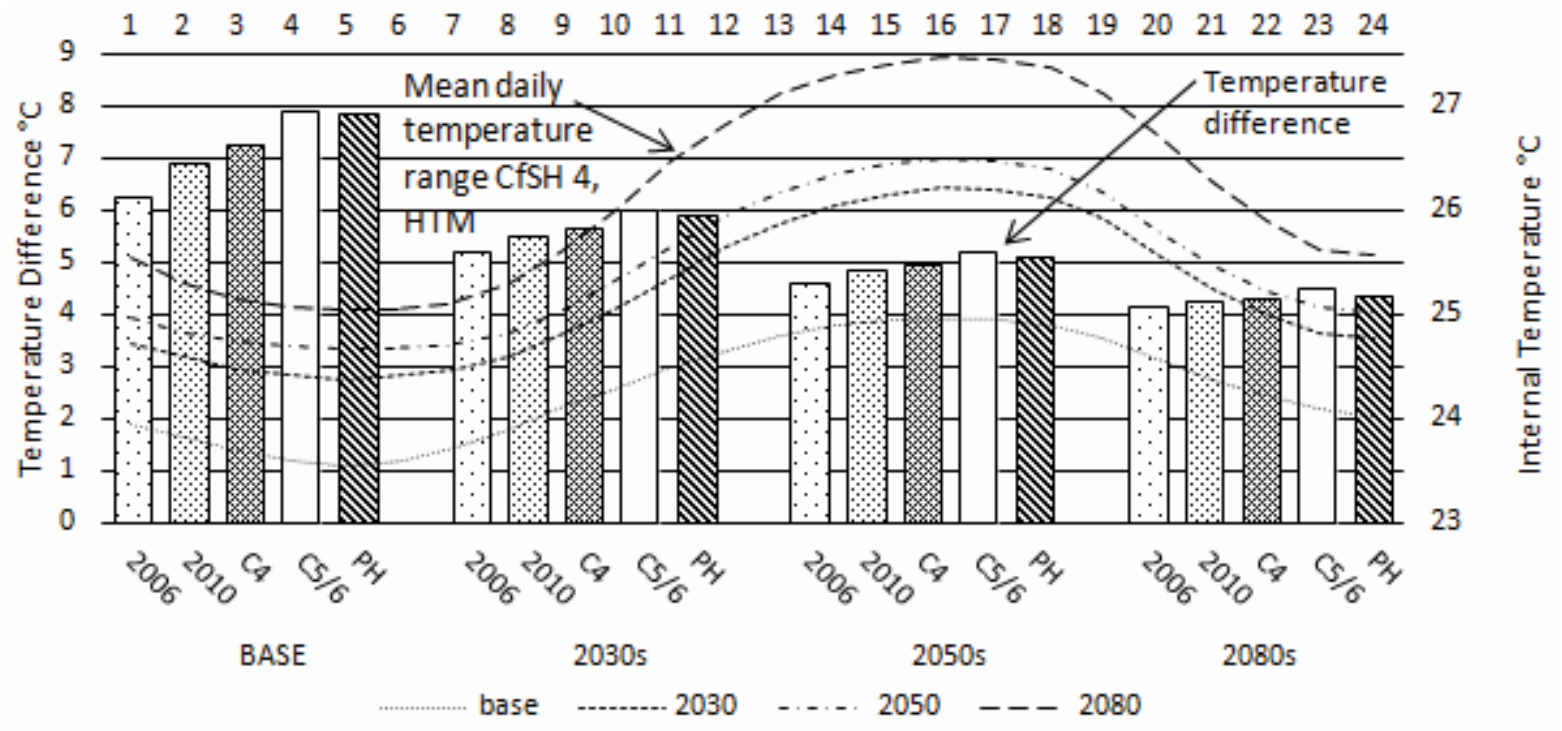

Figure 3 Internal to External Temperature Difference (high thermal mass)

When considering the performance of the buildings across the range of standards (Part L 2006 to the Passive House Standard), during peak temperatures (taken as the month of August) it was found that as the levels of insulation increase and external temperatures increase over time, increasing levels of fabric gains are observed overnight (see Figure 4). This overnight gain maybe a contributory factor in high night-time bedroom temperatures. Figure 4 is based on mean daily temperature ranges for August, showing a comparison between the 2050s and 2080s for dwellings built to the Part L 2006 and CfSH level five building standards. 
2050 - Medium Thermal Mass (August)

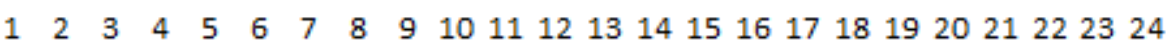

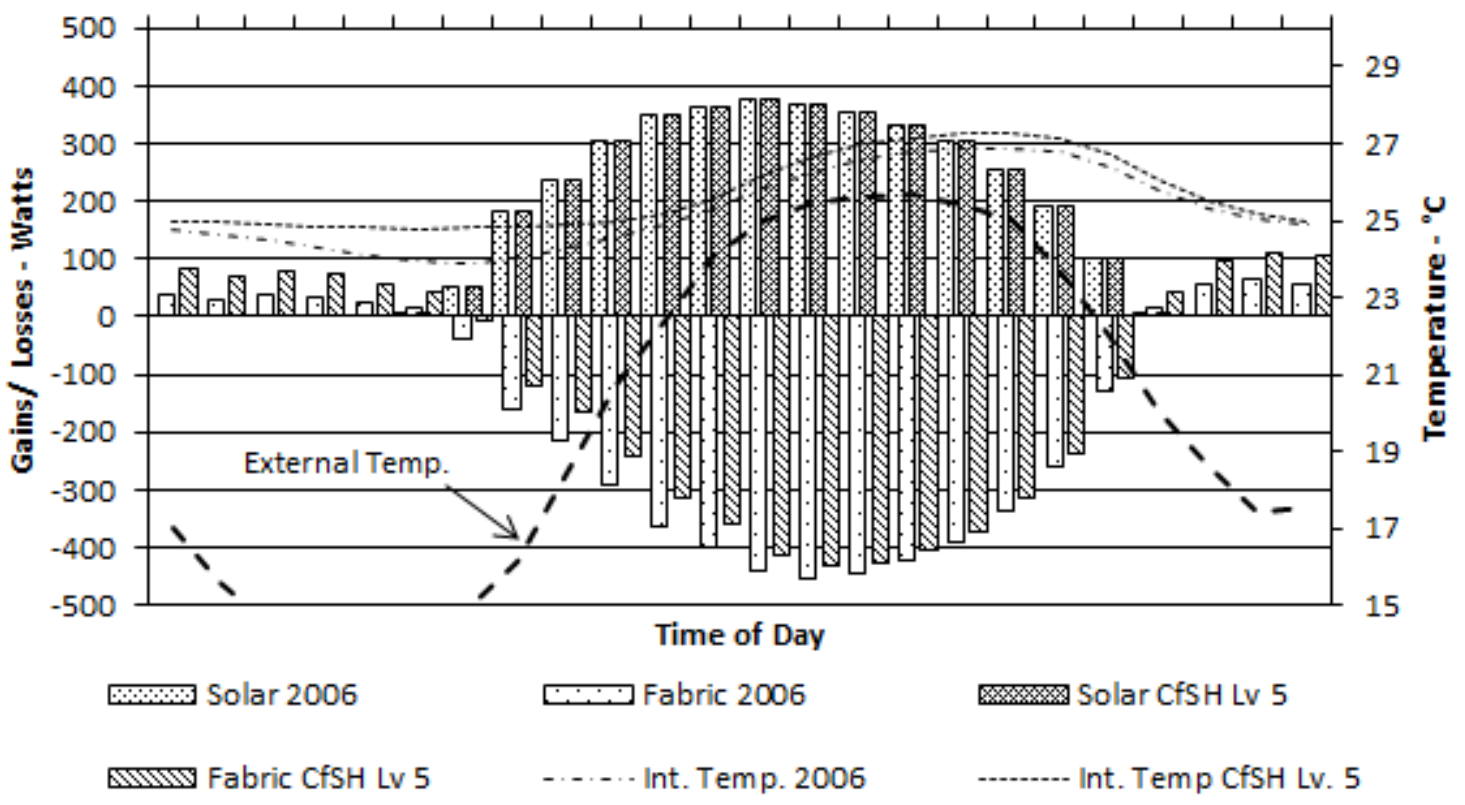

2080 - Medium Thermal Mass (August)

$\begin{array}{llllllllllllllllllllllll}1 & 2 & 3 & 4 & 5 & 6 & 7 & 8 & 9 & 10 & 11 & 12 & 13 & 14 & 15 & 16 & 17 & 18 & 19 & 20 & 21 & 22 & 23 & 24\end{array}$

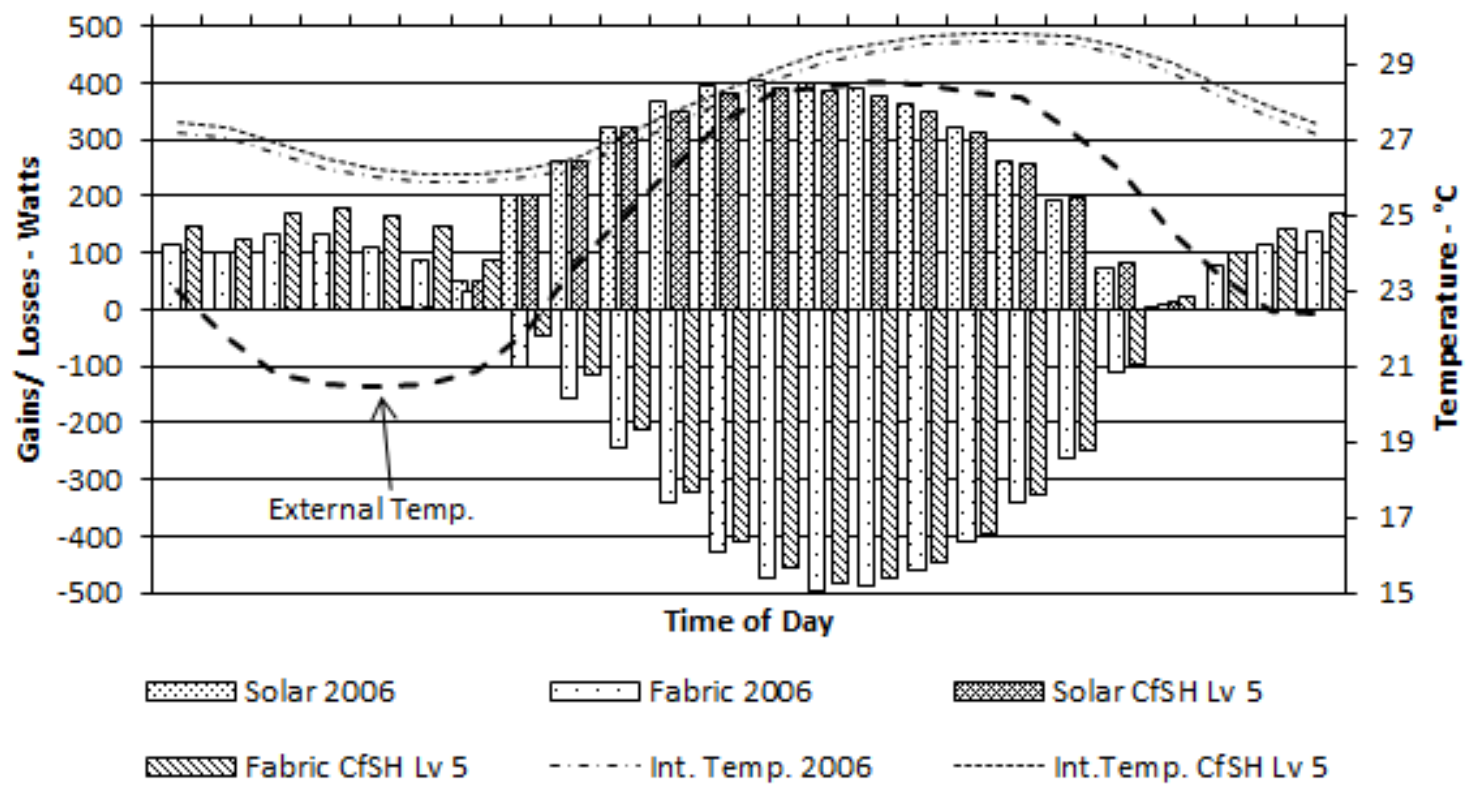

Figure 4 Gains \& Losses (2050 and 2080 comparing Part L 2006 and CfSH level five)

As previously noted, the adaptive comfort criteria include an assessment of the severity and duration of the overheating (criteria two in this study). As can be seen in Figure 2, in the low and medium thermal mass scenarios, as higher levels of insulation are introduced ( $\mathrm{CfSH}$ level four and 
five and Passive House) from the 2030s onwards this criteria is regularly exceeded unless windows are in the half open position. Such window opening as previously noted may be impractical due to noise, pollution and security issues. Consistent exceedance of this criteria is an additional cause for concern as persistent exposure to elevated temperatures can result in serious health impacts, particularly when they occur at night-time (Dengel \& Swainson 2012). This criteria does not consider longer term exposure to higher temperatures (beyond the length of time within a single day) which although of importance was beyond the scope of this paper.

Using the adaptive comfort criteria, a cross analysis between the five building standards (see Table 5) found that, for the slightly open window position in the 2030s (near future) and low thermal mass construction, the 2006 building overheats $5.9 \%$ of the time, the 2010 building overheats $15 \%$ of the time, CfSH level four $18.2 \%$ of the time, $\mathrm{CfSH}$ level five $35.9 \%$ of the time and the Passive House building $31.3 \%$ of the time, all measured during the summer months (May to September inclusive).

Building on this, and extrapolating the data in Table 5, it can be said that in the above scenario building standard (assuming thermal mass is kept constant) can increase potential incidents of overheating by up to $11.7 \%$ in the base case $(11.7-0)$, for the 2030 s this can increase to $30 \%$ (35.9$5.9), 30.7 \%$ in the 2050 s $(41.8-11.1)$ and for the 2080 s $48.4 \%(61.4-13)$. It is worth noting that although the fabric specifications of CfSH level five and the Passive House Standard are similar (when in 'free running' mode) there is evidence that the overheating assessment criteria in the Passive House Standard are more robust. Reductions in incidents of overheating of $6.6 \%$ were observed for the 2030 s, $6.8 \%$ for the 2050 s and $7.2 \%$ for the 2080 s for the Passive House standard in comparison to the $\mathrm{CfSH}$ level five, all based on a medium thermal mass scenario with slightly open windows (data stated but not presented in separate table). As noted below however, orientation presents a significant overheating risk for the Passive House standard, which if shading is not carefully considered, may reduce or reverse the benefit. 
As can be seen from Figure 2, changing the orientation of the building from North-South to EastWest has a noticeable impact on the incidents of overheating across all standards, when measured against the adaptive comfort criteria. This highlights the importance of solar shading and the impact it can have on overheating (East-West orientations are more difficult to shade than North-South orientations due to the low sun angle). For the East-West orientation, in line with the findings from the North-South orientation, further increases in incidents of overheating are experienced as the building standard increases (greater levels of insulation and reduced infiltration), and the building is optimised for heat retention.

For comparative purposes, thermal performance simulations were also carried for Edinburgh in the 2080s (see Figure 2). Unsurprisingly, this resulted in significantly reduced levels of predicted overheating, with in all scenarios, only the low thermal mass version of $\mathrm{CfSH}$ level four and all thermal mass versions of CfSH level five and the Passive House standard presenting significant overheating issues. By comparison, for London all standards exhibited at least some incidents of significant overheating, with the low thermal mass version (excluding the 2006 version) experiencing this across all window opening positions.

\section{Implications}

The preceding results suggest that the current standards used in relation to overheating risk in dwellings in cool climates may not be fit for purpose. The lack of regulation in relation to maximum allowable temperatures and the opportunity for designers to utilise potentially unrealistic adaptations at the design stage, such as window opening, results in unreliable predictions. Coupled with this, the use of historic climatic data means that the current approach is not able to make predictions about likely overheating risk beyond the point of handover, thus ignoring the lifecycle of the building and potential impact of climate change. As noted by Meikle and Connaughton (2006) new and existing housing is predicted to have to last for an extended period and in many cases this 
may be beyond the end of the century. In this context an alternative approach is required if the regulatory framework is to ensure the delivery of comfortable and healthy dwellings that offer resilience to predicted climate change.

In addition to the issues raised with the approach to assessing overheating risk in dwellings, the drive to reduce energy use in new dwellings through current and emerging regulations and building standards (thus optimising the building for heat retention) has the potential to increase the overheating risk. The high proportion of $\mathrm{CO}_{2}$ emissions that have been linked to the built environment (43\% of all CO2 emissions in the UK, DCLG 2015), and the link between this and anthropogenic climate change, creates a particular challenge for regulation in the built environment, where increased short or near term energy savings must be balanced against increased long term overheating risk.

The approach outlined in this paper and the findings as presented in Figure $\mathbf{2}$ could be used as the basis of an alternative risk based overheating assessment method that takes account of predicted climate change. This would require a careful definition of how exposure to high temperatures for a specific period of time constitutes an unacceptable overheating risk, which would provide clarity and allow methods to be developed and refined accordingly.

In addition to this, such an approach could also incorporate climate change adaptation planning at the design stage, as outlined by Jones et al. (2013), thus ensuring that short or near term energy efficiency is not compromised for longer term comfort (by for instance adding shading now, that may reduce future overheating risk, but also increase current heating loads).

\section{Conclusion}

Although the current drive within the regulatory framework of the built environment to reduce heat loss (in cool climates) is not without its merits, as levels of insulation increase and infiltration 
decreases, there is increasing risk of summer time overheating linked to climate change, particularly in urban areas. Furthermore, there is a risk of extended periods of overheating and unacceptably high temperatures in bedrooms overnight. The current standards used for predicting overheating risk may not be fit for purpose as they are based on historic data taking no account of potential climate change, and make unrealistic assumptions in terms of occupant adaptations. Higher levels of thermal mass and the potential for increased ventilation rates offer benefits, however these may reduce over time as internal to external temperature differences decrease.

Predicting overheating in buildings, given the range of variables involved, is complex and subject to a degree of uncertainty. Instead of a single temperature or hours of exceedance metric requiring complex building simulation to predict overheating, a risk based scale may be more appropriate. This risk based assessment, embedded in regulations and standards, could take account of the duration of the high temperatures experienced and the predicted impact of climate change (taking account of not only increased temperatures, but the reduced ability of thermal mass and ventilation to minimise overheating). The approach to climate change risk assessment in dwellings as detailed in this paper could be expanded upon to provide such a design stage risk assessment for a range of dwelling types. This approach presents a clear role for standards and regulations in defining anticipated scenarios in relation to overheating risk linked to climate change with the aim of ensuring resilience in both the predicted 'normal' future climate and during 'extreme' events.

This research must be considered in the context of a number of limitations. Future predictions of overheating risk based on building simulation are subject to uncertainty and rely on a number of assumptions in relation to variables that cannot be easily predicted (such as internal gains, occupancy patters and occupant adaptations). The paper has tried to reduce this uncertainty through the use of $50^{\text {th }}$ percentile climate predictions (using weather data files produced from the PROMETHEUS project), offering a range of possible adaptations (window opening) and taking conservative predications in relation to internal gains, in order to avoid more extreme and 
potentially less realistic predictions. The research presented is based on a single building type, namely a semi-detached dwelling where cross ventilation is possible, but consideration of a wider range of buildings using the same methodology would be of benefit. Further granularity could be added to the predictions by considering a range of shading configurations. For all standards considered the buildings are assumed to be in 'free running' mode, as such this ignores the potential for a Passive House dwelling with a mechanical ventilation system and summer by-pass to implement purge ventilation, although as noted, the benefits of increased ventilation may reduce over time.

Further research is needed to consider how occupants of dwellings, particularly vulnerable occupants, may adapt to overheating. This could include further research in relation to window opening patterns in urban areas where noise, pollution and security may place restrictions on such adaptations.

\section{References}

Beizaee, A., Lomas, K. \& Firth, S. (2013). National survey of summertime temperatures and overheating risk in English homes. Building and Environment, 65, 1-17.

doi:10.1016/j.buildenv.2013.03.011

Chartered Institution of Building Services Engineers (2015). CIBSE Guide A: Environmental Design. London: Chartered Institution of Building Services Engineers.

Coley, D., Kershaw, T. \& Eames, M. (2012). A comparison of structural and behavioural adaptations to future proofing buildings against higher temperatures. Building and Environment, 55, 159-166. doi:10.1016/i.buildenv.2011.12.011

The Committee on Climate Change (2014). Managing climate risks to well-being and the economy: Adaptation sub-committee progress report 2014. Retrieved from Committee on Climate Change: https://www.theccc.org.uk/wp-content/uploads/2014/07/Final_ASC-2014_web-version.pdf

Cotterell, J. \& Dadeby, A. (2012). The Passivhaus Handbook: A practical guide to constructing and retrofitting buildings for ultra-low energy performance. Devon: Green Books.

Crawley, D. (2008). Estimating the impacts of climate change and urbanization on building performance. Journal of Building Performance and Simulation, 1, 91-115.

doi:10.1080/19401490802182079 
de Dear, R., Kim, J., Candido, C. \& Deuble, M. (2015). Adaptive thermal comfort in Australian school classrooms. Building Research \& Information, 43, 383-398. doi:10.1080/09613218.2015.991627

Dengel, A. \& Swainson, M. (2012). Overheating in new homes: A review of the evidence. Retrieved from the Zero Carbon Hub:

http://www.zerocarbonhub.org/sites/default/files/resources/reports/Overheating in New HomesA review of the evidence NF46.pdf

Departments of Communities and Local Government (2011). Cost of building to the code for sustainable homes. London: Departments of Communities and Local Government.

Department of Communities and Local Government, (2014a). House Building: September Quarter 2014. Retrieved from gov.uk:

https://www.gov.uk/government/uploads/system/uploads/attachment data/file/382244/House B uilding Release - Sept Qtr 2014 - revised.pdf

Department of Communities and Local Government, (2014b). English housing survey headline report. Retrieved from Gov.uk:

https://www.gov.uk/government/uploads/system/uploads/attachment data/file/406740/English H ousing Survey Headline Report 2013-14.pdf

Department of Communities and Local Government, (2014c). Dwellings Stock Estimates 2013, England. Retrieved from gov.uk:

https://www.gov.uk/government/uploads/system/uploads/attachment data/file/285001/Dwelling Stock Estimates 2013 England.pdf

Department of Energy and Climate Change (2014). The government's standard assessment procedure for energy rating of dwellings. Retrieved from the Building Research Establishment: http://www.bre.co.uk/filelibrary/SAP/2012/SAP-2012 9-92.pdf

Department of Energy and Climate Change (2015). 2010-2015 government policy: energy efficiency in buildings. Retrieved from Gov.uk: https://www.gov.uk/government/publications/2010-to-2015government-policy-energy-efficiency-in-buildings/2010-to-2015-government-policy-energyefficiency-in-buildings

Department of Health, Social Services and Public Safety (2011). Residential care homes: Minimum standards. Retrieved from rqia.org.uk: http://www.rqia.org.uk/cms resources/care standards residential care homes August 2011.pdf

de Wilde, P. \& Coley (2012). The implications of a changing climate for buildings. Building and Environment, 55, 1-7. doi:10.1016/j.buildenv.2012.03.014

de Wilde, P. \& Tian, W. (2011). Towards probabilistic performance metrics for climate change impact studies. Energy and Buildings, 43, 3013-3018. doi:10.1016/j.enbuild.2011.07.014

Eames, M., Kershaw, T. \& Coley, D. (2011). On the creation of future probabilistic design weather years from UKCP09. Building Services Engineering Research and Technology, 32, 127-142. doi: $10.1177 / 0143624410379934$

Feist, W. (2013). The Passive House Planning Package (PHPP). Passivhaus Institute, Darmstadt 2013. 
Jones, K., Mulville, M. and Brooks, A. (2013). FM, Risk and Climate Change Adaptation. In Alexander, K. (Ed.), EuroFM Journal: International Journal of Facilities Management: Conference papers $12^{\text {th }}$ EuroFM research symposium (pp.120-128). Naarden: EuroFM Publicaitons.

Kendrick, C., Odgen, R., Wang. X. and Baiche, B. (2012). Thermal mass in new build UK housing: A comparison of structural systems in future weather scenarios. Energy and Buildings, 48, 40-49. doi:10.1016/i.enbuild.2012.01.009

Gupta, R. \& Gregg, M. (2012). Using UK climate change predictions to adapt existing English homes for a warming climate. Building and Environment, 55, 20-42. doi:10.1016/i.buildenv.2012.01.014

Hacker, J, Holmes, M., Belcher, S., \& Davies, G. (2005). Climate Change and the Indoor Environment: Impacts and Adaptation. London: The Charted Institution of Building Services Engineers.

Health and Safety Executive (2013). Workplace (Health, Safety and Welfare) Regulations 1992. Retrieved from Hse.gov.uk: http://www.hse.gov.uk/pUbns/priced/l24.pdf

Her Majesty's Treasury (2015). Fixing the foundation: Creating a more prosperous nation. Retrieved from Gov.uk:

https://www.gov.uk/government/uploads/system/uploads/attachment data/file/443897/Productiv ity Plan print.pdf

Hills, G. (2012). Getting the measure of fuel poverty, final report of the fuel poverty review (CASE report 72). Retrieved from London School of Economics and Political Science:

http://sticerd.Ise.ac.uk/dps/case/cr/CASEreport72.pdf

Hulme, J., Beaumont, A. \& Summers, C. (2011). Energy follow-up survey 2011, Report 9: Domestic appliances, cooking \& cooling equipment (BRE report number 288143). Retrieved from Gov.uk: https://www.gov.uk/government/uploads/system/uploads/attachment data/file/274778/9 Domes tic appliances cooking and cooling equipment.pdf

Jenkins, D., Ingram, V., Simpson, S. \& Patidar, S. (2013). Methods for assessing domestic overheating for future building regulation compliance. Energy Policy, 56, 684-692.

doi:10.1016/i.enpol.2013.01.030

Jenkins, D., Patidar, S., Banfill, P.F. \& Gibson, G. (2011). Probabilistic climate projections with dynamic building simulation: Predicting overheating in dwellings. Energy and Buildings, 43, 17231731. doi:10.1016/j.enbuild.2011.03.016

Jenkins, G.J., Murphy, J.M., Sexton, D.M., Lowe, J.A., Jones, P. \& Kilsby, C.G. (2009). UK Climate Projections: Briefing report. Retrieved from metoffice.gov.uk:

http://ukclimateprojections.metoffice.gov.uk/media.jsp?mediaid=87868\&filetype=pdf

Jenkins, K., Hall, J., Glenis, V., Kilsby, C., McCarthy, M., Goodess, C., ......Smith, D. (2014). Probabilistic spatial risk assessment of heat impacts and adaptations for London. Climate Change, 124, 105-117. doi:10.1007/s10584-014-1105-4

Johnson, H., Kovats, R.S., McGregor, G., Stedman, J., Gibbs, M. \& Walton, H. (2005). The impact of the 2003 heat wave on daily mortality in England and Wales and the use of rapid weekly mortality 
estimates. Retrieved from Eurosurveillance.org:

http://www.eurosurveillance.org/ViewArticle.aspx?Articleld=558

Kunkel, S., Kontonasiou, E., Arcipowska, A., Mariottini, F. \& Atanasiu, B. (2015). Indoor air quality, thermal comfort and daylight: Analysis of residential building regulations in eight EU member states. Retrieved from Bpie.eu:

http://bpie.eu/uploads/lib/document/attachment/120/BPIE IndoorAirQualityThermalComfortDayli ght 2015.pdf

Larsen T. \& Jensen R. (2011, November). Comparison of measured and calculated values for the indoor environment in one of the first Danish Passive houses. Paper presented at building simulation 2011: Conference of international building performance simulation association (IBPSA), Sydney, Australia. Retrieved from https://www.ibpsa.org

Lewis, P. \& Alexander, D. (1990). HTB2: A flexible model for dynamic building simulation. Building and Environment, 25, 7-16. doi:10.1016/0360-1323(90)90035-P

Marsh, A. (1996, December). Performance Modelling and Conceptual Design. Paper presented at building simulation 1996: Conference of international building performance simulation association (IBPSA), Sydney, Australia. Retrieved from https://www.ibpsa.org

Mavrogianni, A., Taylor, J., Davies, M., Thoua, C. \& Kolm-Murray, J. (2015). Urban social housing resilience to excess summer heat. Building Research \& Information. 43, 316-333.

doi:10.1080/09613218.2015.991515

Mavrogianni, A., Wilkinson, P., Davies, M., Biddulph, P. \& Oikonomou, E. (2012). Building characteristics as determinants of propensity to high indoor summer temperature on London dwellings. Building and Environment, 55, 117-130. doi:10.1016/j.buildenv.2011.12.003

McLeod, R.S., Hopfe, C.J. \& Kwan, A. (2013). An investigation into the future performance and overheating risks in Passivhaus dwellings. Buildings and Environment, 70, 189-209.

doi:10.1016/j.enpol.2010.08.027

Meikle, J. \& Connaughton, J. (2006). How long should housing last? Some implications of the age and probable life of housing in England. Construction Management and Economics, 12, 315-321.

doi:10.1080/01446199400000041

Mlecnik E, Schütze T, Jansen S, de Vries G, Visscher H \& van Ha A. (2012). End-user experiences in nearly zero-energy houses. Energy and Buildings, 49, 471-478. doi:10.1016/i.enbuild.2012.02.045

National House Building Council (2014). Housing supply update (Issue 68). Retrieved from National House Building Council:

http://www.nhbc.co.uk/ExternalAffairs/documents/HousingNewsletters/filedownload,57892,en.pdf

National House Building Council Foundation (2009). Zero Carbon Homes - an introductory guide for house builders. Retrieved from the Zero Carbon Hub:

http://www.zerocarbonhub.org/sites/default/files/resources/reports/Zero Carbon Homes Introdu ctory Guide for House Builders \%28NF14\%29.pdf 
Naughton, M., Henderson, A., Mirabelli, M., Kaiser, R., Wilhelm, J., Kieszak, ..... S., Rubin, C. (2002). Heat-related mortality during a 1999 heat wave in Chicago. American Journal of Preventative Medicine, 22, 221-227. doi:10.1016/S0749-3797(02)00421-X

Nicol, F. \& Humphreys, M. (2010). Derivation of the adaptive equations for thermal comfort in freerunning buildings in European standard EN15251. Building and Environment, 45, 11-17. doi:10.1016/j.buildenv.2008.12.013

Nicol, F. \& Spires, B. (2013). Climate Change and the Indoor environment: impacts and adaptations. London: The Charted Institution of Building Services Engineers.

Office for National Statistics (2011). Social Trends: Housing. Retrieved from Ons.gov.uk:

http://www.ons.gov.uk/ons/rel/social-trends-rd/social-trends/social-trends-41/housing-chapter.pdf

Parry, M., Canziani, O., Palutikof, J.P., van der Linden P. \& Hanson, C. (Eds.). (2007). Contribution of Working Group II to the Fourth Assessment Report of the Intergovernmental Panel on Climate Change, 2007. Cambridge and New York: Cambridge University Press.

Peacock, A., Jenkins, D. \& Kane, D. (2010). Investigating the potential of overheating in UK dwellings as a consequence of extant climate change. Energy Policy, 38, 3277-3288.

doi:10.1016/j.enpol.2010.01.021

Porritt, S., Cropper, P., Shao, L. \& Goodier, C. (2012). Ranking of interventions to reduce dwelling overheating during heat waves. Energy and Buildings, 55, 16-27. doi:10.1016/j.enbuild.2012.01.043

Roaf, S., Brotas, L. \& Nicol, F. (2015). Counting the cost of comfort. Building Research \& Information, 43, 269-273. doi:10.1080/09613218.2014.998948

Roberts-Hughes, R. (2011). The case for space: The size of England's new homes. Retrieved from Architecture.com:

https://www.architecture.com/Files/RIBAHoldings/PolicyAndInternationalRelations/HomeWise/Cas eforSpace.pdf

Rodrigues, L., Gillott, M. \& Teltow, D. (2013). Summer overheating potential in a low-energy steel frame house in future climate scenarios. Sustainable Cities and Societies, 7, 1-15.

doi:10.1016/i.scs.2012.03.004

Schild, P.G. (2013). Norway: Impact, compliance and control of legislation. Retereived from Buildup.eu: http://www.buildup.eu/publications/8491

Schnieders J. A (2005). A first guess passive home in southern France. Passive-On Project report. Retrieved from Une maison passive à Nice: http://www.maison-passivenice.fr/documents/FirstGuess Marseille.pdf

Skinner, C. \& Grimwood, C. (2005). The UK noise climate 1990-2001: population exposure and attitudes to environmental noise. Applied Acoustics, 66, 231-243.

doi:10.1016/j.apacoust.2004.07.009

Statistics for Wales (2015). Dwelling Stock Estimates for Wales, 2013-2014. Retrieved from Gov.wales: http://gov.wales/docs/statistics/2015/150429-dwelling-stock-estimates-2013-14-en.pdf 
Sustainable Energy Authority of Ireland (2013). Introduction to DEAP for professionals. Retrieved from Seai.ie:

http://www.seai.ie/Your Building/BER/BER Assessors/Technical/DEAP/Introduction to DEAP for Professionals.pdf

van Hoff, T., Blocken, B., Henson, J. \& Timmermans, H. (2014). On the predicted effectiveness of climate change adaptation measures for residential buildings. Building and Environment, 82, 300316. doi:10.1016/i.buildenv.2014.08.027

Wright, A., Young, A. \& Natarajan, S. (2005). Dwelling temperatures and comfort during the August 2003 heat wave. Building Services Engineering Research \& Technology, 26, 285-300.

doi:10.1191/0143624405bt136oa

Wang, X., Chen, D. \& Ren, Z. (2010). Assessment of climate change impact on residential building heating and cooling energy requirement in Australia. Building and Environment, 45, 1663-1682. doi:10.1016/j.buildenv.2010.01.022

The Zero Carbon Hub (2015). Assessing overheating risk: Evidence review. Retrieved from Zerocarbonhub.org: http://www.zerocarbonhub.org/sites/default/files/resources/reports/ZCHOverheatingEvidenceReview-Methodologies.pdf 